\title{
Cervical cytology screening and government policy
}

\author{
Sheila K Ross
}

\begin{abstract}
Objective-To assess the coverage of cervical cytology screening in one general practice surgery according to the criteria in the new Scottish general practitioner contract and to explore the difficulties of defining performance in such screening.

Design-Review of annual analysis of uptake of screening during 1984-8.

Setting-Suburban general practice surgery in Glasgow serving 3000 patients.

Patients-All women aged 35-64 registered in 1984 increasing in 1988 to all women aged 20-64.

Main outcome measure-Assessment of uptake of smear tests and reasons for smear not being taken and of the effect of these outcomes on the new general practitioner contract.

Results-The numbers and percentages of women having a smear test in the previous five and three years were recorded, and the reasons why a smear was not taken were defined in the remainder (hysterectomy, test not offered, risk not known, test declined, patient moved away, and patient unaccounted for). In $1988,85 \%(608 / 719)$ of the women aged 30-64 and 80\% (693/870) of those aged 20-64 had had a smear test in the previous five years. An appropriate or irreducible reason for the lack of a smear test was defined in all the others.

Conclusions - The population studied contained a substantial number of women in whom cervical smear was unnecessary, inappropriate, or refused. These factors and the likely demographic variation in the uptake of smear tests have important implications for the setting and achieving of the government's targets for cervical cytology screening.
\end{abstract}

\section{Introduction}

Cervical cytology has become prominent since the government issued general practitioners with a new contract, one aim of which is to achieve higher rates of screening for carcinoma of the cervix by replacing item of service payments by target payments. ${ }^{1}$ It is suggested that $80 \%$ of women aged $20-64$ on a general practitioner's list should have been tested at some time during the previous five years, possibly with lower payments for lower rates of uptake. I examined the results of cervical cytology screening in my general practice and here highlight the difficulties of both acquiring verification of tests done and defining an appropriate eligible population to be screened.

\section{Patients and methods}

The practice, of just over 6000 patients, covers an area shaped like a dumb bell. The study was carried out in a suburban surgery attended by 3000 of the patients, who are mainly from occupational classes I-III; the remainder attend a village surgery. The practice has four full time partners, three men and one woman (SKR), and a full time trainee. Each surgery has a part time nurse and office staff in attendance from 830 am to $6 \mathrm{pm}$, except for one hour at lunch time.

Patients are encouraged to book an appointment for a cervical smear test during an ordinary surgery session when the nurse is present so that she can complete the necessary forms and check the patient's weight and blood pressure and analyse a urine sample. Thus the patients enjoy a certain anonymity of purpose for their visit to the surgery. All pelvic examinations and smears are carried out by a doctor.

The age range of the women studied widened from 35-64 in 1984 to 30-64 in 1985 and 20-64 in 1988, with analysis of the uptake of screening during the previous five and three years from 1986. In 1987 and 1988 the reasons why a cervical smear was not taken were also categorised as "hysterectomy," "moved away," "not offered" (because the woman was a virgin or we considered it inappropriate to offer a smear), "declined" (after several invitations to attend), and more recently "not known if at risk." This last category covered women aged 20-29 who were not known to be sexually active; unlike in older women we did not consider it appropriate to pursue such women to attend for a smear test without knowing their degree of risk.

\section{Results}

All female patients in the age range on the surgery register were included. The table shows the results. The highest uptake of smear tests was in the women aged 30-64 in whom the uptake could not be increased because a reason had been identified for all those who were not tested. When younger women were included fewer were screened.
Glasgow G44 3QG Sheila K Ross, FRCPGLAS, general practitioner

Cervical cytology uptake and reasons for smears not being taken. Values are numbers (percentages) of women unless stated otherwise

\begin{tabular}{|c|c|c|c|c|c|c|c|c|c|c|}
\hline \multirow[b]{2}{*}{ Year } & \multirow[b]{2}{*}{$\begin{array}{l}\text { Age range } \\
\text { (years) }\end{array}$} & \multirow[b]{2}{*}{$\begin{array}{c}\text { Total No of } \\
\text { patients }\end{array}$} & \multicolumn{2}{|c|}{ Smear taken during: } & \multicolumn{6}{|c|}{ Reason for smear not being taken } \\
\hline & & & Past 5 years & Past 3 years & Hysterectomy & Not offered & $\begin{array}{c}\text { Risk } \\
\text { not known }\end{array}$ & Declined & Moved away & $\begin{array}{c}\text { Not } \\
\text { accounted for }\end{array}$ \\
\hline 1984 & $35-64$ & 454 & $308(68)$ & & $30(7)$ & & & & & \\
\hline 1985 & $30-64$ & 694 & $499(72)$ & & $38(5)$ & & & & & \\
\hline 1986 & $30-64$ & 699 & $543(78)$ & $479(69)$ & $32(5)$ & & & & & \\
\hline 1987 & $30-64$ & 722 & $585(81)$ & $511(71)$ & $45(6)$ & $22(3)$ & & $26(4)$ & $31(4)$ & $13(2)$ \\
\hline 1988 & $30-64$ & 719 & $608(85)$ & $549(76)$ & $49(7)$ & $21(3)$ & & $26(4)$ & $15(2)$ & \\
\hline 1988 & $25-64$ & 785 & $653(83)$ & $590(75)$ & $49(6)$ & $21(3)$ & $15(2)$ & $26(3)$ & $19(2)$ & $2(<1)$ \\
\hline 1988 & $20-64$ & 870 & $693(80)$ & $622(71)$ & $49(6)$ & $22(3)$ & $52(6)$ & $26(3)$ & $24(3)$ & $4(<1)$ \\
\hline
\end{tabular}


An almost irreducible proportion of $18 \%$ of women will not be screened (table). Between $9 \%$ and $10 \%$ were not tested for valid clinical reasons either because they were not at risk or because it was judged inappropriate to offer a test, a further $6 \%$ had a possible valid reason in that their degree of risk was not known, and another $3 \%$ with no clinical reason chose to decline having a smear test. To add on to this $18 \%$ is the small proportion of women who could not be traced or accounted for: overall, $20 \%$ of women were not given smear tests. Under the proposed new contract general practitioners are to assess their performance in screening from their own lists. For them to be paid the health boards have to agree from their register of the general practitioners' patients that the $80 \%$ uptake has indeed been achieved. Given the evidence that there is wide discrepancy between these lists, ${ }^{2}$ the possibility of agreement that $80 \%$ have been screened seems remote.

Tests performed outside primary care were recorded for one year. Despite almost certain underrecording on our part and underreporting by community and hospital doctors such tests amounted to $12 \%$ of the total. Although only some tests in multiparous women and those over 35 qualify for item of service payment, $105(46 \%)$ of the 230 cytology tests performed in 1988 did so. I took 175 (over 75\%) of these smears.

\section{PROBLEMS IDENTIFIED}

Women who are not at risk are easy to identify in theory but much less so in practice, except perhaps those who have had a hysterectomy. If a woman does not have a cervix she cannot have a cervical smear test; a vaginal smear may be taken but the purpose is different. About one in five women have had a hysterectomy by the age of $65,{ }^{3}$ and the operation is performed 6500 times a year in Scotland. ${ }^{4}$ It is not related to social class, and an average list of 2500 in England and Wales contains 80 such women. ${ }^{3}$ Women who have never had sexual intercourse are also not at risk. As far as postmenopausal women are concerned, Feffcoate's Principles of Gynaecology states that if a woman has had a series of smear tests with negative results by the age of 55 there is no need for further tests. $^{5}$

Clinical judgment-Several groups of women are at risk but to offer them a smear test is inappropriate because of medical, psychiatric, and psychological reasons. A few (less than 1\%) were considered to be physically unfit to have the test, including those who were housebound owing to advanced multiple sclerosis, paresis, or terminal illness. One woman was mentally handicapped with Down's syndrome and was thought to be not at risk, though there was the additional problem of informed consent. In a much larger group of women the reasons were temporary or potentially so. Patients with anorexia nervosa were not offered a smear and neither were those who had a psychotic episode, and sometimes in those with a severe anxiety state the offer was deferred. A few patients in whom smear taking had failed were transferred to this category. Women who had been recently widowed were also excused. This is surely the art rather than the science of medicine and has more to do with quality of care than with achieving the arbitrary uptake of a screening procedure.

Patients whose risk is not known - If girls are sexually active screening should be encouraged. The difficulty is to know whether they are at risk if they are nulliparous, not married, or not known to be using contraception. Women generally attend general practitioners' surgeries more often than men, and young women also have a disproportionately high rate of registration in accuracies. ${ }^{6}$ They have highly variable lifestyles, which are often not known to their general practitioner. This applied to 52 of the 151 women aged
20-29 in my practice and is in sharp contrast with some areas of the city where single parenthood is the norm by the age of 20 . We thought it insensitive to invite such patients for smear tests and instead opted to mark on their records that a test may be due and when they attended surgery ascertain the need for a test. This policy failed, however, as these patients tend not to consult their general practitioner.

Patients who declined a smear test-Patients have the right to decline a screening test. With continuing health education and awareness and pressure from the media, however, the number in this group will fall but not disappear. Their wishes must be respected. Although we have emphasised the importance of cervical cytology screening in this practice for 15 years, at least $4 \%$ of women aged $30-64$ still do not want to have a smear test. At least as many might be expected in the younger women whose risk is not known if they were invited to attend. Standing and Mercer could not persuade $5 \%$ of their women at risk to be screened.

Patients who are not traceable or have moved away-I found that in a small stable population between $2 \%$ and $4 \%$ of patients could not be traced. Firstly, patients may have moved outside the practice area. In one study of patients on general practitioners' registers $8 \%$ could not be traced; $7 \%$ were on the family practitioner committee register and $1 \%$ were only on a general practitioner's list. ${ }^{6}$ In a report by Rang and Tod in a middle class London surgery $48 \%$ of all the letters sent to women aged 35-44 were returned "undelivered"; the average for all women aged 30-64 was 30\%. Secondly, registration inaccuracies exist, particularly when patients move within a practice area or do not report a change of name. The inadequacies of registers and the problem this poses for screening were recently highlighted by Bowling and Jacobsen. ${ }^{9}$ The solution awaits improved information technology. On average $10 \%$ of the addresses on a general practitioner's register are inaccurate and $5 \%$ of the dates of birth ${ }^{6}$ Inaccurate dates of birth pose an additional but generally unacknowledged problem, although I did not encounter it in this study.

Time since previous test-For new patients on a general practitioner's list accurate information is essential for this kind of survey. This depends on the timely receipt of good medical records as women rarely remember accurately when they had a cervical smear unless one was taken postnatally or they have their own written confirmation. Older women in particular underestimate the time from their previous test. The lag time in receiving records is already many months if the patient crosses boundaries. If it becomes easier for patients to change doctor this may aggravate the problem. Central recording of smear tests may seem an attractive alternative for cytology, but it may not work: in a recent report on immunisations recorded by a local authority $40 \%$ instead of $72 \%$ were recorded. ${ }^{10}$

Record of cervical smear test-The advantages of a patient being screened in primary care are that the result comes directly to the general practitioner, is filed in the proper place in the patient's records, and is accessible at any time. Results of tests carried out elsewhere tend to get filed with other letters, so unless special care is taken the results can become buried in the case notes. The new cytology forms used by the Greater Glasgow Health Board enable the doctor taking the smear to pass on the top copy of the result to the general practitioner and retain the yellow copy for his or her own records. In future the laboratory will be asked to send a copy to the general practitioner irrespective of where the test was done as well as inform the recall computer. This is a step in the right direction and should overcome the problem of clinics that do not pass on results to general practitioners - for example, genitourinary clinics, where patients at high risk of 
cancer of the cervix are screened. The situation is analogous to the problem of infection with HIV: general practitioners are least likely to receive information on patients for whom they most need it.

Place where test performed-A record not only of when a patient has been screened but also of whether it was done outside primary care may become necessary for remuneration purposes. Cervical cytology screening may be done in the community, in hospital, and privately. In some places young women favour family planning clinics and older women well women clinics to have their smear tests. In the area of the Greater Glasgow Health Board $63 \%$ of the 65000 smear tests performed in 1985 were carried out in the community and hospital clinics, leaving only $37 \%$ done in general practice (G Mcllwain, personal communication). Gynaecologists will presumably continue to screen patients who are already under their care. Some obstetricians routinely take smears at antenatal clinics, which serves as a valuable safety net in places with a low uptake of screening and in women at high risk of cervical cancer. Some employers provide medical services that include cytology screening. About $5 \%$ of smear tests are done privately in the Glasgow area.

Abnormal results of clinical importance-The increasing number of women with smear tests showing clinically important changes are referred to a specialist and so are transferred out of general practice or community screening. In 1986, 361626 smears were taken in Scotland, of which 2330 gave positive results and 18983 were suspicious or atypical. In 1987, 420361 cervical smears were taken; 3859 gave positive results and 21688 were suspicious or atypical. ${ }^{3}$

\section{Discussion}

Since becoming a principal in general practice 15 years ago I have consistently offered women a cervical smear test. I was disappointed to find that only $68 \%$ of the women aged 35-64 had been tested by 1984 Cytology testing is, however, like painting the Forth Bridge: as soon as you think you have finished you start again. Each year up to 1988 more women have come forward for testing. Some who have not previously been tested accept a second or third invitation, some are influenced by friends or the media, and some are influenced by our enthusiastic trainees. Symptoms bring others forward. In retrospect, screening the first $68 \%$ of women was the easy part; thereafter it got progressively more difficult, with about a $5 \%$ yearly increase in uptake in 1985 and 1986 and then a smaller increase until all the women aged 30-64 in the practice were accounted for and $85 \%$ of them tested in the previous five years (table). If the dilution effect of widening the age range to $20-64$ is considered the uptake is less $(80 \%)$ mainly because of the large group (one third of the 20-29 year olds) whose risk is not known. To screen over $80 \%$ of women took 15 years, although computer recall may well speed things up.

The difficulties in ascertaining risk in single women should not be underestimated. The subject is sensitive and many doctors think that they should not be coerced into inquiring into or condoning certain modes of behaviour.

Women's preference for a female doctor for cervical screening was almost $60 \%$ in a postal survey. "But the presence of a female partner in a practice has not been shown to be associated with a higher rate of organised cervical screening. ${ }^{12}$ Nevertheless, if there is a female doctor she is likely to perform most of the tests, and if the number of women doctors is reduced in general practice as a result of government policy this may well have greater repercussions on the screening programme than expected.

The date of a patient's last smear test needs to be reliably recorded and accessible irrespective of whether the patient was screened in primary care. The new contract indicates that all women aged 20-64 on a general practitioner's list ("the target population") are to be included for calculation of payment and requires that $80 \%$ are screened. It says, "the target is reached if $80 \%$ of these women have been screened during the five years preceding the claim." It is confusing to use the same word, target, for both the population to be tested and also for the proportion of that population actually screened. These are two separate issues. The first should be the group of women within the age range who are eligible for testing and the second the percentage uptake of the test.

Indeed, the wording in the section about the target population ("women aged 20-64 during the last five years preceding the claim") might suggest that women up to the age of 69 are to be included. Many of these older women are unlikely to want a test. Furthermore, if screening postmenopausal women with previous negative results is unnecessary this is hardly a worthwhile exercise. All it will achieve is that even fewer general practitioners reach the $80 \%$ rate of uptake necessary for payment. The upper age limit should be lowered not raised, otherwise smears will be taken to attain the target instead of for the potential benefit of the patient.

Patients who have already had one smear test are more likely to attend for another ${ }^{13}$; indeed, patients at low risk in general are more likely to attend for health checks. ${ }^{14}$ The reasons why women from some ethnic minority groups do not attend are touched on by McAvoy and Sharma. ${ }^{15}$

The new contract's requirement for the same percentage uptake in different socioeconomic areas is unrealistic. For instance, 14\% of those in occupational classes IV and V responded to an invitation to attend for a smear, increasing to only $42 \%$ after major input, including an interview. ${ }^{16}$ The Black report Inequalities in Health spells out the difficulties. ${ }^{17}$ In my study more than $12 \%$ of tests were performed outside primary care in one year, which is probably representative for this practice. Given that the $80 \%$ rate that triggers payment had been reached, the $12 \%$ outside primary care would not qualify for remuneration under the new contract. Indeed, none at all might qualify if there was a discrepancy between my list and the list the health board holds: both are to be used with the health board's list verifying the general practitioner's. Given the documented discrepancies between these lists, this can only eliminate and not facilitate general practitioners in receiving proper reward for the work they do and will inevitably mean more time spent in administration. It may even act as a disincentive to some general practitioners.

Perhaps the purpose of cervical cytology as a screening procedure is becoming lost. Surely the aim is to reduce the morbidity and mortality from carcinoma of the cervix. An eligible group that contains only those at risk needs to be defined. In addition, women who are being treated for the condition cannot be considered appropriate for screening. Women will exercise their right to decline tests, targets or no targets, and it will continue to be much more difficult to motivate those in the lower occupational classes to be screened. The proposed target, $80 \%$ of all women aged $20-64$, is unrealistic, even in a general practice with a special interest in cervical cytology screening.

1 Scottish Home and Health Department. A new contract. The government's detailed proposals for changes to the GP's terms of service and remuneration system in Scotland. Edinburgh: SHHD, 1989.

2 Fraser RC, Clayton DG. The accuracy of age-sex registers, practice medical records and family practitioner committee registers. $\mathcal{F} R$ Coll Gen Pract 1981;31:410-9.

3 McPherson A. Women's problems in general practice. 2nd ed. Oxford: Oxford University Press, 1988:113. 
+ Common Services Agency, Information and Statistics Division. Scottish health statistics 1988. Edinburgh: ISD Publications, 1988

Tindal VR. Feffcoate's principles of gynaecology. 5th ed. London: Butterworth, 1987.

6 Sheldon MG, Rector AC, Boriman PA. The accuracy of age-sex registers in general practice. I R Coll Gen Pract 1984;34:269-71.

Standing P, Mercer S. Quinquennial cervical smears; every woman's right and every general practitioner's responsibility. Br Med $f$ 1984;289:883-6.

8 Rang EH, Tod EDM. Problems of cervical screening programmes. $f R$ Coll Gen Pract 1988;37:540-3.

Bowling A, Jacobsen B. Screening: the inadequacy of population registers. Br Med J 1989;298:545-6.

10 Pennington E, Wilcox RML. Immunisation, practice records and the white paper. I $R$ Coll Gen Pract 1988;38:515-6.

Nichols S. Women's preference for sex of doctor: a postal survey. $\mathcal{F} R$ Coll Gen Pract 1987;37:540-3.
12 Havelock C, Edwards R, Cuzick J, Chamberlain J. The organisation of cervical screening in general practice. $\mathcal{f} R$ Coll Gen Pract 1988;38:207-11.

3 Sanson CD, MacInerny J, Oliver V, Wakefield J, Yule R. Recall of women in a cervical screening programme: an estimate of the rate of response. British fournal of Preventive and Social Medicine 1975;29:131-4.

14 Pill R, French J, Harding K, Stott N. Invitation to attend a health check in a general practice setting: comparison of attenders and non attenders. $f R$ Coll Gen Pract 1988;38:53-6.

15 McAvoy B, Sharma S. Asian women and contraception. The Physician 1986;5:1067-8.

16 Nathoo V. Investigation of non-responders at a cervical screening clinic in Manchester. BrMed F 1988;296:1041-2.

17 Townsend P, Davidson N, eds. Inequalities in health. The Black report. 1st ed. England: Penguin, 1982

(Accepted 5 fune 1989)

\title{
Attendance and non-attendance for breast screening at the south east London breast screening service
}

\author{
James McEwen, Erica King, Graham Bickler
}

\begin{abstract}
Objectives-To ascertain the reasons for a low rate of response for breast screening.

Design-All relevant aspects of the organisational process examined, including general practitioners' notes. Non-responders visited and interviewed.

Setting-An inner city breast screening service working on the model advocated by the Forrest report.

Subjects - 288 Women aged 50-64 registered with several general practices and invited for screening by post.

Main outcome-Determination of factors important for success of breast screening programmes.

Results-After five women were excluded by their general practitioners the response rate was 129 out of $283(46 \%)$, but $99(35 \%)$ of the women did not receive their invitations because of inaccuracies in the family practitioner committee's database and general practitioners failing to check women's addresses completely.

Conclusions-Increased rates of response will depend on enabling general practitioners to check addresses and on an increased awareness of the importance of information.
\end{abstract}

\section{Introduction}

After the publication of the Forrest report ${ }^{1}$ and its acceptance by the Department of Health and Social Security, Camberwell Health Authority was identified as the site for the first breast screening centre in South East Thames Regional Health Authority. Screening started in 1988, but the rate of response was well below the $70 \%$ figure proposed as a target in the Forrest report. We followed up cohorts of women in several screening batches to identify the nature of the problem. The population register used as the basis of breast and other screening programmes was thought to be important. ${ }^{2}$

Description of screening system-The local scheme follows the methods recommended in the Forrest report. The family practitioner committee's computer produces screening batches - that is, lists of women aged 50-64 from several general practitioners who are to be invited for breast screening. These are sent to the individual general practitioners as prior notification lists for amendment to addresses, names, dates of birth, and unsuitability on clinical grounds. When the prior notification lists are returned the family practitioner committee's computer is updated and the revised list is sent to the screening office. This issues personalised invitations in the general practitioner's name with fixed appointment times. Women who do not attend are sent a second invitation. Women who have not attended after two letters of invitation are classed as non-attenders, and their general practitioners are sent a non-responder card for inclusion in their notes.

\section{Methods}

We examined each stage of the screening process. The numbers of women at each stage were checked from the records of the family practitioner committee and screening office. The prior notification lists that had been returned to the family practitioner committee by general practitioners were examined to ascertain how of ten addresses had been altered. The addresses of non-attenders whose invitations were not returned by the post office were checked in the postcode directory. The checked addresses that were found to exist were visited by two interviewers to identify and interview the occupier. The reasons for non-attendances were noted for all the non-attenders who were contacted, and they were offered a further invitation to attend for screening. General practitioners' records were checked to ascertain what further information they contained about the addresses of $(a)$ women whose invitations had been returned unopened by the post office; $(b)$ non-attenders whose addresses could not be found in the postcode directory; and $(c)$ non-attenders whose addresses were visited but who were found to have moved.

\section{Results}

The screening batches contained 288 women registered with several different practices. Seventeen out of 20 prior notification lists were returned. As a result, five of the 288 women were excluded from screening, 37 addresses had major changes made to them (sufficient to have otherwise led to non-delivery of the letter), and nine had minor changes. The figure summarises the results.

Overall, 283 women were sent invitations. Ten contacted the screening office to say that they would not be coming for screening (see table). A total of 44 invitations were returned unopened by the post office. When the general practitioners' notes for these 44 were examined, 17 contained major address changes, four minor changes, and 15 no changes. Eight sets of notes could not be found. No further follow up was undertaken for these women, though the family practitioner
Correspondence to: $\mathrm{Dr}$ Bickler.

$B r M e d ~ \mathcal{F} 1989 ; 299: 104-6$ 